\title{
Transit-oriented development for older adults: A survey of current practices among transit agencies and local governments in the US
}

\author{
Michael Duncan \\ Florida State University \\ mdduncan@fsu.edu \\ Yazmin Valdez Torres \\ Florida State University \\ yjv11@my.fsu.edu
}

\author{
Kristin Gladwin \\ Florida State University \\ kss07c@my.fsu.edu \\ Mark Horner \\ Florida State University \\ mhorner@fsu.edu
}

\author{
Brittany Wood \\ Florida State University \\ bsw05@my.fsu.edu
}

\begin{abstract}
This study seeks to examine the ways in which transit agencies and local governments have been considering the transportation needs of older adults when planning for transit-oriented development (TOD). Surveys with representatives from a sample of transit agencies $(n=15)$ and local governments $(n=31)$ from across the US were conducted. Few of the surveyed agencies indicated that they had specific practices that encourage TOD to help meet the transportation needs of older adults. Respondents identified the cost of development, market forces, and the lack of specific amenities for older adults as the primary barriers to attracting aging groups to TOD.
\end{abstract}

\section{Article history:}

Received: May 14, 2021

Received in revised form:

September 17, 2021

Accepted: October 22, 2021

Available online: February 22, 2021

\section{Introduction}

Over the past few decades, urban planners have embraced transit-oriented development (TOD) as a means of creating sustainable communities (Bernick \& Cervero, 1997; Cervero, 1998; Renne, 2017). Although different government agencies have their own specific definitions of TOD (Cervero, Murphy, Ferrell, Goguts, \& Tsai, 2004; Belzer \& Autler, 2002), at the most basic level, TOD can be physically defined as a walkable, mixed-use development clustered around a transit station. This type of development pattern will ideally allow residents to easily and conveniently reach a variety of activities both inside the TOD (on foot) or outside the TOD (by transit) without needing a private automobile. Thus, advocacy of TOD often points to its potential to facilitate a reduction in how much individuals and households drive and the associated negative effects of this driving (e.g., emissions, collisions, physical inactivity (Cervero \& Sullivan, 2011; Newman, Beatley, \& Boye, 2017). However, in focusing on driving reductions, one can lose sight of TOD's potential to contribute to social equity goals. A TOD can provide a high level of access and, thus, a higher quality of life, to those who cannot (or should not) drive due to physical limitations or because they cannot afford their own car (although the affordability of TOD housing comes into question for the latter group).

Older adults constitute a large and growing segment of the population. According to Fernald (2014), one in five people in the U.S. will be 65 and older by 2030. Furthermore, Foley, Heimovitz, Guralnik, and Brock (2002) estimate that more than 600,000 older adults stop driving each year in

Copyright 2021 Michael Duncan, Kristin Gladwin, Brittany Wood, Yazmin Valdez Torres \& Mark Horner http://dx.doi.org/10.5198/jtlu.2021.1798

ISSN: $1938-7849$ | Licensed under the Creative Commons Attribution - Noncommercial License 4.0

The Journal of Transport and Land Use is the official journal of the World Society for Transport and Land Use (WSTLUR) and is published and sponsored by the University of Minnesota Center for Transportation Studies. 
the US. When an older adult stops driving, whether that is by choice or because it is no longer safe for them to drive, maintaining mobility and quality of life becomes difficult, particularly for those residing in communities that have limited transportation options.

Conversely, residing in a TOD could allow older adults to maintain independent mobility after they stop driving by providing nearby transit options, as well as providing a built environment that offers a variety of activities within walking distance from one's home. However, the literature about TOD is largely devoid of more than a cursory mention of how it might be used to support successful aging. To our knowledge, this study represents the first systematic effort to better understand if, to what degree, and how, older adults are taken into consideration in the design and implementation of TOD. We view this as an important first step in broadening the TOD-related research agenda to include some consideration of the aging population.

After surveying staff at municipal planning departments and transit agencies across the US, we found that most of these agencies have policies that encourage TOD and seek to provide better transportation for older adults. However, these are usually separate endeavors. Few agencies claimed to have specific practices that encourage TOD for older adults. Only one transit agency was able to point to a written document that links TOD with serving aging populations. It appears that discovering, developing, and implementing such practices will require additional thought and effort from both academics and planning professionals.

\section{$2 \quad$ Literature review}

\subsection{Transit-oriented development}

The existing and growing body of literature on TOD covers many different aspects. Early work sought to simply define TOD and its benefits (Bernick \& Cervero, 1997; Boarnet \& Compin, 1999; Cervero, Ferrell, \& Murphy, 2002). Others then built upon this by developing typologies of TODs and examining how they fit together within a larger transit system (Dittmar \& Shelley, 2004; Kamruzzaman, Baker, Washington, \& Turrell, 2014; Schlossberg \& Brown, 2004). There was also much initial work in terms of identifying barriers to building TOD and the policies and practices that could overcome them (Belzer \& Autler, 2002; Cervero et al, 2004; Hess \& Lombardi, 2004).

Once TODs became established on the ground, researchers began to examine the type of households they attract and to what extent they increased transit usage, decreased vehicle ownership, and decreased vehicle miles traveled (Cervero, 2007; Chatman \& DiPetrillo, 2010; Dill, 2008; Duncan, 2017; Lund, 2006; Nasri \& Zhang, 2014). Additional work has examined whether TOD positively influences property values (Atkinson-Palombo, 2010; Duncan, 2011; Mathur \& Ferrell, 2013). Some have taken a critical view of the TOD property value premium as a catalyst for gentrification that may serve to displace or repel lower income households (Brown, 2016; Chapple \& Zuk, 2016; Fan \& Guthrie, 2012; Rayle, 2015). Others have countered this by arguing that even with higher housing cost, the lower transportation cost in a TOD makes it more affordable on balance (Renne, Tolford, Hamidi, \& Ewing, 2016).

The present study parallels those that have examined TOD-driven gentrification because it is concerned with the ability of TOD to effectively accommodate those that stand to benefit most from it. Where the gentrification literature focuses on low-income households that could benefit from the transportation cost savings associated with living in a TOD, this study focuses on aging populations that can benefit from the enhanced transportation options provided by a TOD as they make the difficult transition away from driving. Thus, chronicling existing efforts to encourage aging-friendly TOD provides an important and unique contribution to the TOD literature. 


\subsection{Older adults' need for transportation options}

The loss of independence and feelings of isolation associated with driving cessation often lead to a significant decline in mental and physical health (Chihuri, et al., 2016; Kerr, Rosenberg, \& Frank, 2012; Marottoli, et al., 1997; Ragland, Satariano, \& MacLeod, 2005). However, providing good access to needed and desired activities by walking and transit can, at least partially, mitigate the negative health impacts (Adler \& Rottunda, 2006; Marquet \& Miralles-Guasch, 2015; Michael, Green, \& Farquhar, 2006).

The majority of older adults today reside in auto-centric suburban and rural areas (Rosenbloom, 2003), and numerous studies mention the lack of public transportation as one of the major challenges for older adults (Coughlin \& D'Ambrosio, 2012; Eby \& Molnar, 2009; Gould, 2015; Kerschner \& Silverstein, 2018; Leistner \& Steiner, 2017; Rosenbloom, 2009).

For older adults who have transitioned away from driving, walking plays an important role in maintaining mobility independence. Based on data collected during the 2002 National Transportation Availability and Use Survey, walking accounts for almost 1 in 4 trips made (Sweeney, 2004). As walking is often mentioned as one of the most realistic transportation options for older adults beyond the personal automobile, and since walking is also necessary for all other forms of transportation (walk to transit stops, walk to the car etc.) it is considered the second most important form of travel for older adults (Rosenbloom, 2009). However, many older adults do not consider their neighborhood to be pedestrian-friendly (Harrell, Lynott, \& Guzman, 2014).

Community design can have a direct impact on older adults' ability to live independently postdriving cessation, particularly in regard to accomplishing household sustaining travel (Kerr et al., 2012). TOD provides a possible planning framework by which communities can allow older adults to maintain their mobility independence as they transition away from driving.

\section{Research design}

\subsection{Research questions}

This study focuses on three specific research questions:

1. To what degree are transit agencies and local governments actively involved in encouraging TOD for aging populations and in what ways are they doing so?

2. What do practitioners perceive as the barriers to creating TOD that attracts aging residents and effectively meets their needs?

3. Are practitioners aware of transit stations and/or specific TOD projects within their jurisdictions that are good examples of places that attract and meet the needs of aging residents?

To answer these questions, surveys were conducted with representatives from transit agencies that operate fixed-guideways systems and local governments that have fixed-guideway systems within their municipal boundaries. Fixed-guideways were selected because previous research indicated that the majority of TODs are in large rail-served cities (Cervero et al., 2004).

Transit agencies and local governments are the two primary government stakeholders in the implementation of TOD projects. Transit agencies are important because they control the delivery of the transit systems around which TOD is built. In addition, properties adjacent to stations, which can be used for TOD implementation, are sometimes owned by transit agencies. Larger transit agencies commonly have in-house real estate development staff working to negotiate joint developments around transit sta- 
tions (Cervero et al., 2004). Transit agencies can take on various additional roles in the implementation of TOD, ranging from education and advocacy to active development partners or funders (Cervero et al., 2004). Finally, transit agencies have a stake in encouraging TOD because it can generate increases in ridership and associated revenue gains.

Local governments play a large role in the creation of TOD through their ability to regulate and control land use and development around stations that fall within their jurisdictions (Cervero et al., 2004). In addition, TOD may contribute to economic productivity, which can directly benefit local governments. More specifically, revitalization of declining neighborhoods, increased affordable housing, monetary gains derived from joint development opportunities, and tax revenue generation are some of the potential benefits of TOD that might appeal to local governments (Brooks, 2010).

\subsection{Sample selection}

Transit agencies that operate fixed-guideways systems and local governments that have a fixed-guideway system within their boundaries were identified using the National TOD database generated by the Center for Transit Oriented Development. This database provides the location for every existing fixedguideway transit station in the US. To focus on larger transit systems that provide significant accessibility improvements for nearby residents, stations that are part of smaller transit systems, such as BRT, ferries, streetcars, people movers, shuttles, and trolleys, were excluded from the analysis. Based on the criteria mentioned above, 46 transit agencies that operate a fixed-guideways system were identified, and all of them were invited to participate in the survey.

There were 622 cities identified with at least one fixed-guideway station. Sixty-three percent of the cities $(n=392)$ had only one station within their municipal boundaries. The rest of the cities $(n=230)$ had between 2 and 535 stations. To maintain a reasonable sample size, a stratified two-stage design was used in which two cities were selected from each Combined Statistical Area (CSA) in the US. This was done to assure full geographic coverage across US metropolitan areas.

In the first stage of this sampling process, the city with the highest number of stations in each CSA was selected. There were some cities with fixed-guideway stations that did not belong to a CSA. These were grouped by state (Arizona, California, and Texas) and treated as three independent CSAs for sampling purposes. 30 cities were selected by this process. In the second stage, one city was randomly selected from each CSA, resulting in 27 additional cities being chosen. Ultimately, we invited 57 cities to participate in the survey. This sampling approach provided a representation of central cities with a large quantity of stations and suburban cities with a few stations within their municipal boundaries, thus providing diversity within the sample.

Once the transit agencies and local governments were selected, we consulted their websites to determine if they had resources focused on TOD. For those that had a TOD department, a representative from that department was selected. If the agency did not have a TOD-focused office, calls were made to the planning department, development department, or administrative department to obtain information about who would be the best person to take the survey. The survey was conducted from November 2015 through April 2016. Table 1 shows the list of transit agencies and local governments that provided a response.

The transit agency response rate was 32 percent $(n=15)$ and the municipality response rate was 54 percent $(n=31)$. While the final sample size is too small to allow detailed statistical inference, it allowed us to hear from enough practitioners to make inferences about broader trends. Since nearly all survey respondents did not point to any specific written policies, but rather provided general comments, it is important to note that the information provided could be limited to the respondents' personal knowledge and opinions. 
The set of respondents proved relatively representative in terms of the percent of older adults (age 65+) within their jurisdictions. For the 15 transit agency respondents, older adults make up 10 to 19 percent of the population within the different metropolitan areas that they serve, with a median of 14 percent. For reference, older adults make up 14 percent of the population across all US metro areas. For the municipalities, older adults make up 7 to 25 percent of the population within their boundaries, with a median of 11 percent. While the municipal respondents do skew younger, this is to be expected because the large, urban cities typically found along rail corridors tend to have fewer older adults. For example, within the 100 largest US municipalities, older adults make up 12 percent of the population.

Table 1. Transit agencies and municipalities that mentioned having practices focused on transportation for older adults, TOD, and TOD for older adults

\begin{tabular}{|c|c|c|c|c|}
\hline \multirow{2}{*}{\multicolumn{2}{|c|}{ Respondents }} & \multicolumn{3}{|c|}{ currently has practices focused on } \\
\hline & & $\begin{array}{l}\text { Transport for } \\
\text { older adults }\end{array}$ & TOD & $\begin{array}{l}\text { TOD for Older } \\
\text { adults }\end{array}$ \\
\hline \multirow{15}{*}{ 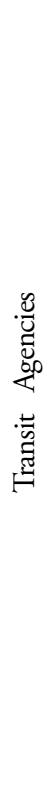 } & DART (Dallas) & No & Yes & No \\
\hline & Denver RTD & Yes & Yes & No \\
\hline & GCRTA (Cleveland) & Yes & Yes & Yes \\
\hline & Hampton Roads Transit (Norfolk) & N/A & N/A & No \\
\hline & Massachusetts Bay Transportation Authority (Boston) & Yes & Yes & Yes \\
\hline & MTA - MD (Baltimore) & Yes & Yes & Yes \\
\hline & PATCO (Philadelphia) & Yes & No & No \\
\hline & Port Authority of Allegheny County (Pittsburgh) & N/A & Yes & No \\
\hline & $\begin{array}{l}\text { Regional Transportation Authority of Northeastern Illinois } \\
\text { (Chicago) }\end{array}$ & Yes & N/A & No \\
\hline & San Diego MTS & No & No & N/A \\
\hline & SFMTA (San Francisco) & Yes & Yes & No \\
\hline & SunRail (Orlando) & Yes & Yes & Yes \\
\hline & Utah Transit Authority (Salt Lake City) & Yes & Yes & No \\
\hline & Valley Metro (Phoenix) & Yes & Yes & No \\
\hline & VRE (Norfolk) & No & No & No \\
\hline
\end{tabular}




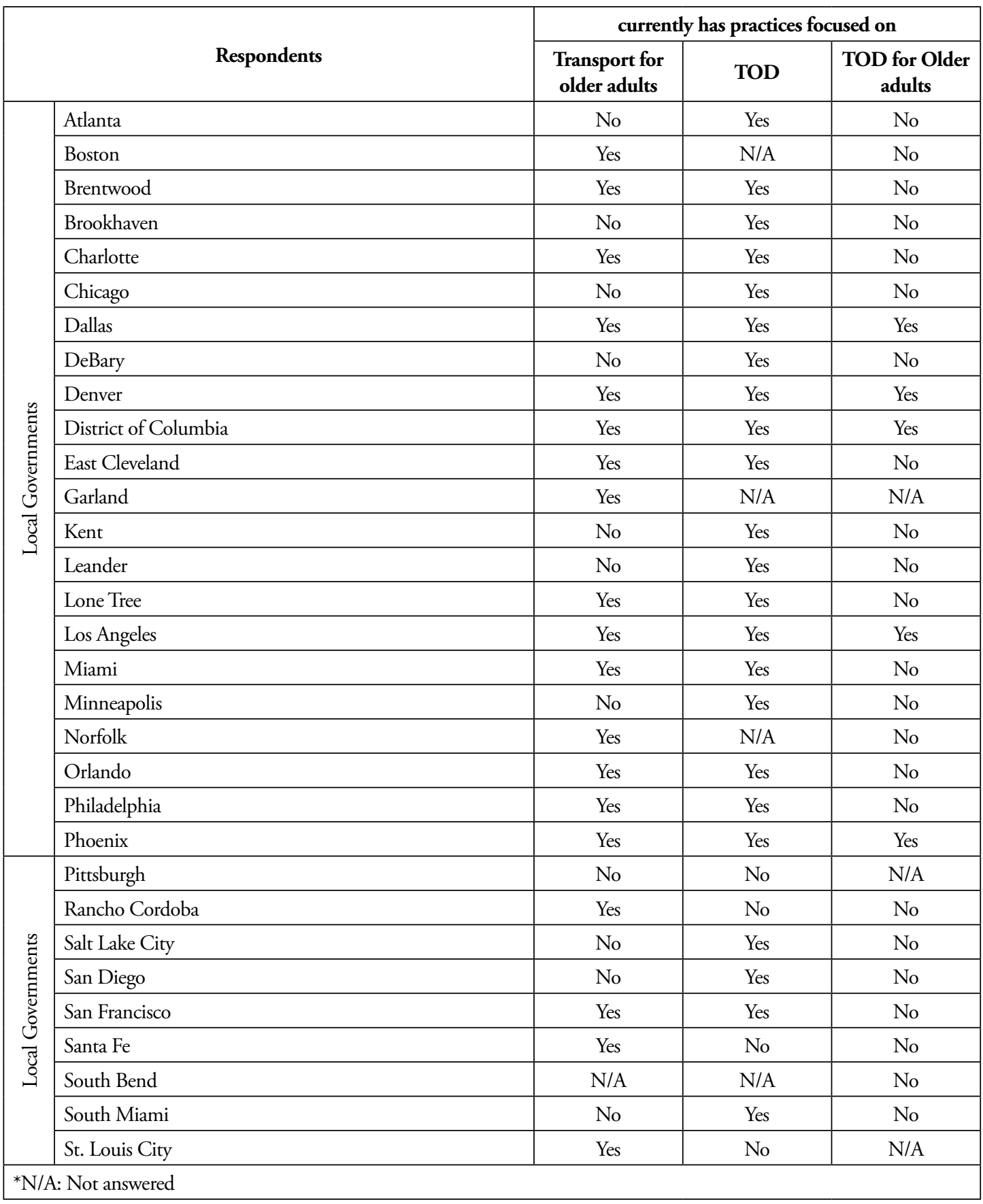

\subsection{Survey instrument}

An online survey was sent by email to agency representatives. A diagram of the survey questions and the order in which they were given is provided in Figure 1. The survey was divided into three sections that correspond to the research questions previously outlined.

Section A had the objective of obtaining information about the ways in which transit agencies and local governments are actively encouraging TOD for older adults. The first set of questions in this section asked about current practices implemented by transit agencies and local governments to improve transportation options for older adults. A second set of questions sought information about current 
practices to encourage TOD without relating them to practices focused on older adults. A final set of questions focused on information about any current practices aimed specifically at encouraging TOD for older adults.

Respondents were first asked a yes/no question as to whether they had practices within the broad categories described above. If they answered yes, they were then asked to describe these practices. Rather than ask them about specific types of practices, an open-ended format was utilized to allow for the possibility that they might be utilizing practices not currently mentioned in the literature or otherwise unknown to the authors. Further, to keep the number of survey questions to a minimum, we wanted to avoid asking a long series of questions about specific practices.

Section B asked about the main barriers to encouraging TOD for older adults (as perceived by the survey respondents). For the reasons described above, a single open-ended question was utilized for this section of the survey. Previous studies (as cited in the literature review) have identified the major barriers to building housing and mixed-use development around transit stations such as increased traffic, parking reduction, land-use policies, and opposition by current residents towards new/increased development. However, the question in this survey went further by asking about the principal barriers to the creation of TODs for older adults. It was expected that these barriers may differ from those previously identified in the literature because of the specific needs and preferences of older adults.

Section $\mathrm{C}$ sought to identify station areas with high concentrations older residents and to understand why these concentrations have occurred, as well as identify specific TOD projects that have made an explicit effort to attract older adults. It merits mention that even a highly knowledgeable practitioner can't be expected to fully evaluate demographic patterns at transit stations or for specific TOD projects. Thus, the lists of stations and projects provided in answer to these questions won't be comprehensive.

Despite not being comprehensive, the survey results from this section can prove useful in several ways. The identified examples demonstrate that TOD can attract (or at least not repel) older populations in a given jurisdiction. They also provide insight about the characteristics that might attract older adults to TOD and provide details on the efforts that were put forth to attract older adults to these TOD projects. Further, the ability of a respondent to point out some specific examples, even if not comprehensive, serves as an indicator of the general knowledge and awareness of practitioners about the potential of TOD to benefits older adults. On a more practical level, the examples identified in this section of the survey provide possible targets for future case studies about TOD for older adults. 


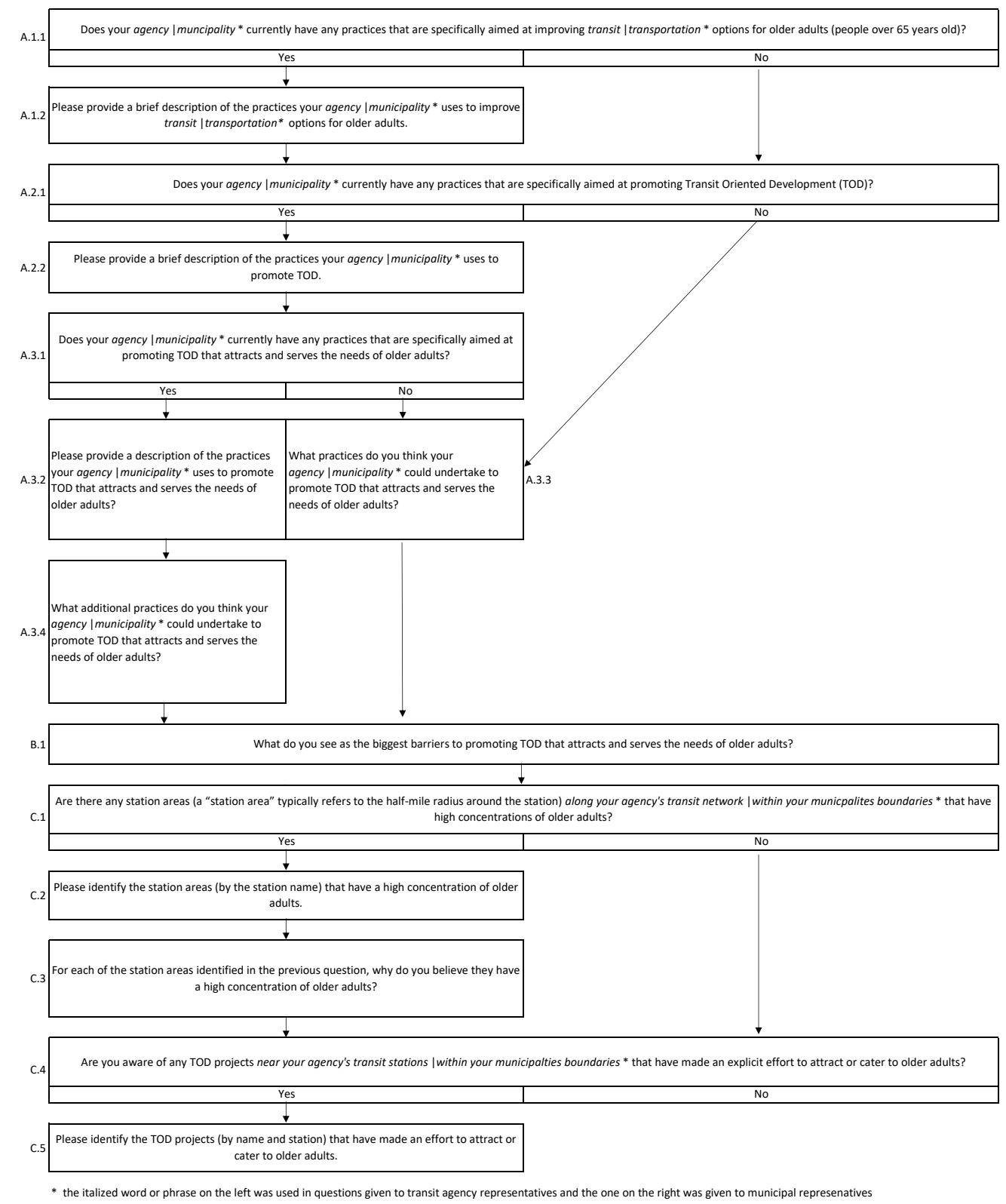

Figure 1. Survey diagram

\subsection{Survey follow-up}

Due to the non-responses or vague responses to key survey questions, follow-up emails and phone calls were made to survey respondents (or substitutes within the same agency) during the months of September through November of 2018. Note that the follow-up communications focused only on two specific questions. Respondents were not asked to revisit any other questions.

More specifically, eight transit agencies and nine municipalities initially provided no response when asked a simple yes/no question about whether they had any practices to encourage TOD for older 
adults. This relatively large number of non-responses did not occur with other similarly worded questions, so this did not seem to be caused by a lack of clarity with the question wording. More likely, they didn't know if they had such practices, particularly given that such practices are uncommon, and could not immediately determine this while taking the survey. By separately following up with them about this particular question, it allowed them to take some time to ask around the office or otherwise investigate. After our follow-up efforts, we received responses for this question from all but one transit agency and three municipalities. In all but one of these follow-ups, they answered that they did NOT have any practices related to TOD for older adults.

We also attempted to follow up with the three transit agencies and five municipalities that said they had practices to encourage TOD for older adults. In the initial survey, those answering yes to this question were then asked to describe these practices. Some skipped this question and others did not provide much detail. As such, we attempted to contact all the respondents that said they had these practices and give them an opportunity to elaborate on their initial survey answers. Unfortunately, only one transit agency responded to repeated attempts to set up an interview.

\section{$4 \quad$ Results and discussion}

Figure 2 summarizes the percentage of transit agency and municipal representative that indicated having practices to improve transportation options for older adults, generally encourage TOD, and to specifically encourage TOD for older populations. Table 1 (as previously presented) shows the responses to these questions for each responding agency. Subsequent sections will explore the responses to these questions in more detail. 
A)Does your transit agency/municipality currently have any practices that are specifically aimed at improving transportation options for older adults (people over 65 years old)?
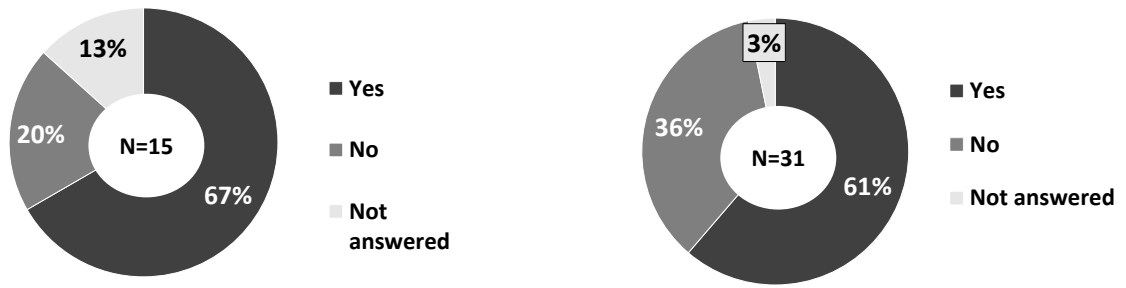

B) Does your transit agency/municipality currently have any practices that are specifically aimed at promoting TOD?
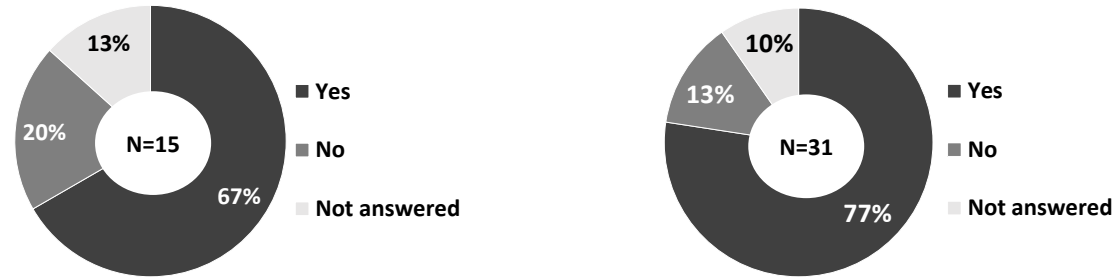

C) Does your municipality currently have any practices that are specifically aimed at promoting TOD that attracts and serves the needs of older adults?
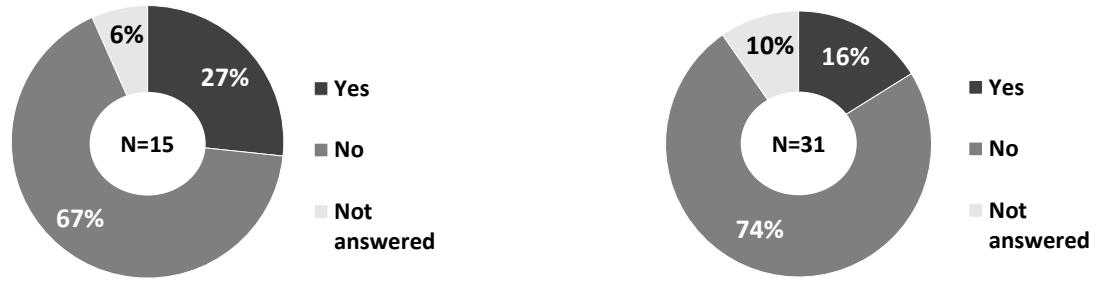

Figure 2. Percentage of transit agencies and local governments that have A) practices to improve transportation options for older adults, $\mathrm{B}$ ) practices to promote TOD, and C) practices to promote TOD for older adults 


\subsection{Improving transportation options for older adults}

When asking transit agencies if they currently have any practices specifically aimed at improving transportation options for older adults, $67( \pm 20)^{1}$ percent indicated that they do. When asked to describe these practices, the main answers provided were:

- Discounted rates or free rides for older adults $(n=8)$

- Safe pedestrian infrastructure around stations $(n=5)$

- Specialized transit or dial-a-ride service $(n=4)$

- Outreach programs to encourage education and training programs for older riders $(\mathrm{n}=1)$

It should be noted that the Americans with Disabilities Act (ADA) requires all transit agencies in the US to provide dial-a-ride (paratransit) services to disabled individuals of all ages (49 CFR Parts 27, 37, 38, and 39). Thus, dial-a-ride service is not specifically aimed at older adults. Further, because it is legally mandated, the provision of dial-a-ride is a poor indicator of an agency's commitment to serving older adults. Nonetheless, because older adults make up a large percentage of dial-a-ride patrons, some respondents listed it anyway.

Approximately $61( \pm 17)^{2}$ percent of local governments indicated they had practices aimed at improving transportation for the older population. The main practices mentioned were:

- Discounted or free rides $(n=9)$

- Transportation assistance programs to provide information about benefits, riding demonstrations and other services $(\mathrm{n}=7)$

- Dial-a-ride services $(\mathrm{n}=7)$

- Partnerships with transit agencies to provide free or discounted rides and dial-a-ride services $(\mathrm{n}=3)$

- Planning to improve older adults' mobility $(\mathrm{n}=2)$

It is noteworthy that some respondents mentioned that their municipality had practices such as discounted or free rides or dial-a ride-services that are typically provided by a transit agency rather than as a municipal service. These respondents may have thought the question was about services available in, but not necessarily provided by, the municipality. In this instance, the question might have been more carefully worded to limit responses to municipal services.

\subsection{Encouraging TOD (in general)}

When asking transit agencies about practices to encourage TOD, $67( \pm 20)$ percent $(n=10)$ indicated they have such practices. The following practices were specifically mentioned:

- Creation ofTOD research/workgroup to implement new projects $(n=5)$

- Acquisition of available parcels around transit stations $(\mathrm{n}=2)$

- Joint ventures with private developers to create TOD projects near major transit facilities $(\mathrm{n}=2)$

- Implementation of TOD strategic plans $(\mathrm{n}=1)$

- Implementation of TOD guidelines $(n=1)$

- Streetscape and pedestrian improvements $(\mathrm{n}=1)$

1 This and all other confidence intervals presented for transit agencies are 95\% intervals based on a sample size of 15 and a total population of 46 .

2 This and all other confidence intervals presented for municipalities are $95 \%$ intervals based on a sample size of 31 and a total population of 622 . 
When asking local governments about their practices to encourage TOD, $77( \pm 14)$ percent $(n=24)$ indicated they currently have such practices. Those mentioned were:

- Increasing density around transit stations $(n=9)$

- Implementation of parking tools such as parking reduction $(\mathrm{n}=7)$

- Implementation of mixed uses $(n=4)$

- Streetscape and pedestrian improvements $(n=4)$

- Implementation of zoning overlays to allow different uses around stations $(\mathrm{n}=4)$

- Implementation of tax increment financing (TIF)

\subsection{Encouraging TOD specifically for older adults}

Only $27( \pm 19)$ percent of transit agencies $(n=4)$ indicated having practices that they believe encourage TOD for older adults. Notably, these four agencies served metro areas with an older adult population of at least 14 percent, which ranks them in the top half of the respondents. These practices were described as follows:

- TOD guidelines heavily oriented to pedestrian and ADA access $(n=3)$

- Encouraging the presence of assisted living facilities near stations $(\mathrm{n}=2)$

- A regional TOD scorecard and implementation plan which includes an "aging in place" strategy $(\mathrm{n}=1)$

Even among the few that indicated they were doing something to encourage TOD for older adults, their descriptions of these practices were relatively vague. For instance, providing $\mathrm{ADA}$ access is required by law and may not be a good indicator of whether any special effort is being made to accommodate older adults. Further, two respondents mentioned that they encourage the presence of nearby assisted living facilities but failed to mention anything specific about how they go about doing so.

When given an opportunity to elaborate on these practices, only one transit agency (the Greater Cleveland Regional Transit Authority) responded. This agency indicated that it relies on the following planning document for their TOD projects: the "Northeast Ohio Areawide Coordinating Agency (NOACA) Regional TOD Scorecard and Implementation Plan". This plan includes an 18-page long strategy that links TOD with Aging-in-Place. According to the agency's website:

Knowing that only a small percentage of older American move after they retire there, and since TOD can improve mobility choices of older adults, the Regional TOD Scorecard and Implementation Plan is going to focus on identifying potential policies and programs for location of housing and services for seniors closer to the fixed route transit system to expand transportation choice. (NOACA, n.d.)

The Aging-in-Place strategy includes directions for defining and choosing communities based on two main categories: 1) "New formation Aging-in Place communities," defined as developments or redevelopments purposefully designed to attract older adults, and 2) Natural Occurring Retirement Communities (NORCs) (NOACA, n.d., p. 3). Bases on the community types, the Aging-in-Place strategy provides specific guidance related to four (4) primary program elements (NOACA, n.d., p. 7):

1. Zoning and Land Use aimed at increasing housing options for older adults. This includes up dates to zoning codes and land use policies that allow mixed use developments, accessory dwell ing units, and to update definitions related to lot types, as well as housing type and size.

2. Mobility Services aimed at increasing transit ridership and mobility options. This includes lo cating senior housing opportunities within TOD areas or within $1 / 4$ to $1 / 2$ mile of transit cor 
ridors and locating businesses that cater to older adult preference and needs along transit lines.

3. Complete Streets and Pedestrian Design strategies aimed at creating safer conditions for all us ers. This includes connected sidewalk networks with shorter block lengths (300-450 ft.), ample sidewalk widths, safe paving materials, and design for seasonal safety.

4. Outreach and Marketing Strategies aimed at engaging and educating stakeholders and older adults. This includes strategies to educate older adults on transit, as well as how to engage older adults in the discussion of housing, services, mobility, and transit.

About $16( \pm 13)$ percent of local governments mentioned having practices to encourage TOD for older adults $(n=5)$. Unlike transit agencies, the municipalities that responded positively to this question had lower percentages of older adults (below 12 percent) relative to other respondents. The practices mentioned include:

- Implementation of ordinances supportive of senior housing and affordable housing $(\mathrm{n}=4)$

- Improving transportation access for seniors $(\mathrm{n}=2)$

It merits mention that the practices indicated by these municipalities lack a specific connection to the promotion of TOD. For example, policies supportive of senior and/or affordable housing may or may not relate to TOD depending on the degree to which such policies are focused on transit station areas.

Those representatives from transit agencies and local governments responding that they currently have practices to encourage TOD for older adults were also asked their opinion about additional practices (not currently being undertaken) that they believe could be carried out to further encourage TOD that attracts and serves older adults. However, none of the respondents answered this question.

Those who did not indicate having any practices to encourage TODs for older adults were similarly asked their opinion of what practices they could undertake to encourage TOD that attracts and serves the needs of older adults. Seven transit agencies responded to this question and provided the following responses:

- Encouraging the presence of affordable and senior housing $(\mathrm{n}=3)$

- Design for walkability, including Universal Design (designing for all ages and abilities) $(\mathrm{n}=1)$

- Providing a mix of uses and services $(\mathrm{n}=1)$

- Long term service planning focus instead of short-term planning $(\mathrm{n}=1)$

Additionally, 19 municipalities responded to this question and provided the following responses:

- Encouraging senior living facilities and affordable housing near transit stations $(\mathrm{n}=11)$

- Improving older adults' education and access to transit ( $n=6)$

- Designing facilities for walkability, including Universal Design ( $n=4)$

- Modifying zoning ordinances to allow more residential and commercial density $(n=2)$

As with the descriptions of existing practices, the descriptions of potential practices were not highly detailed. As the respondents had not been asked to formally consider this issue in their professional activities, detailed strategies could not be expected. However, this does serve to demonstrate the general lack of attention that relevant agencies are giving to the idea of TOD for older adults.

\subsection{Summary of current practices}

In sum, the survey showed 67 percent of transit agencies and 61 percent of local governments mentioned having practices that are specifically aimed at improving transportation options for older adults. Further, 
67 percent of transit agencies and 77 percent of local governments mentioned having practices aimed at encouraging TOD. However, only 27 percent of transit agencies and 16 percent of local governments indicated they had practices to encourage TOD for older adults. With one notable exception (as discussed above), those respondents that indicated they had such practices only provided limited and/or vague examples of these practices. As such, only $7( \pm 10)$ percent of transit agencies and 0 percent of local governments gave an indication of making more than a cursory effort. Even asking simply about potential (rather than actual) practices elicited no response from many of the agencies, and limited responses from others.

While the majority of the respondents appear to be concerned about better serving older adults and facilitating TOD, few of them are considering these in combination. The representatives of relevant agencies don't appear to have considered and/or prioritize using TOD to help older adults. This indicates that there is ample opportunity for agencies concerned with providing better transport option for their older constituents to pursue creative policies that can better facilitate TOD for older adults.

\subsection{Barriers to encouraging TOD for older adults}

About 61 percent of transit agency respondents $(n=9)$ listed possible barriers to TODs for older adults. Some of the barriers mentioned were:

- The cost of development $(\mathrm{n}=3)$

- Low density development $(\mathrm{n}=2)$

- A lack of nearby amenities for older adults $(\mathrm{n}=1)$

- TOD is usually not affordable for older adults $(n=1)$

Some of the barriers identified in this part of the survey apply to TOD in general (e.g., cost, density, affordability), and they are well documented in the broader literature (as previously cited). This lack of specificity regarding older adults is an additional indicator of the lack of thought these agencies give to encouraging TOD for older adults. Lack of nearby amenities for older adults, while only mentioned by one agency, is one barrier that specifically pertains to older adults. Additionally, while the high cost of housing within many TODs applies to all age cohorts, it may be a particularly important barrier for older adults on fixed incomes.

Approximately 65 percent of local government representatives $(n=20)$ provided their opinion regarding what could be the main barriers to TOD for older adults:

- The market dictates the population segments for new housing and currently the housing market focuses on "non-traditional households" or Millennials $(\mathrm{n}=7)$

- Senior facilities compete with more lucrative developments $(\mathrm{n}=1)$

- Not enough fixed transit stops $(\mathrm{n}=1)$

- Cost of housing around stations $(\mathrm{n}=1)$

- Lack of nearby amenities for older adults $(\mathrm{n}=1)$

- $1 / 4$ mile might be a hurdle to an aging population $(n=1)$

- Lack of sidewalks ( $\mathrm{n}=1)$

- Housing preferences $(\mathrm{n}=1)$

The most cited barriers were related to the high cost of development and housing market issues. Regarding cost of development, some private investors see TOD as risky due to the high cost of land assemblage, environmental cleanup, and infrastructure finance (Cervero, Murphy, Ferrell, Goguts, \& Tsai, 2004). This barrier pertains to TOD in general, but high development costs result in TOD projects that are often targeted to higher income residents, leaving many older adults with limited possibilities to benefit from residing in a TOD. 
Regarding market issues, several respondents mentioned that the TOD housing market is targeted to Millennials or non-traditional households, such as "Dual income no kids" or the "Creative professionals" ( $n=7)$. Therefore, senior facilities compete with more lucrative developments $(n=1)$. To overcome these barriers, government aid could reduce the risk (real or perceived) and encourage TOD with affordable housing for older adults by offering developers incentives such as pricing, taxes and charges, subsidies, rebates, grants and loans, rewards, or bonds for including affordable housing options within TOD projects.

\subsection{Existing TOD for older adults}

About $33( \pm 20)$ percent of transit agencies indicated having station areas with high concentrations of older adults ( $\mathrm{n}=5)$ (Figure 3). A follow-up question asked them to identify the three main stations by name and the reason(s) they believed those stations have a high concentration of older adults. However, only two agencies responded to the follow-up question (as described below).

\section{Transit Agencies}

Municipalities

A) Are there any station areas along your agency's transit network/within your municipal boundaries that have high concentrations of older adults?
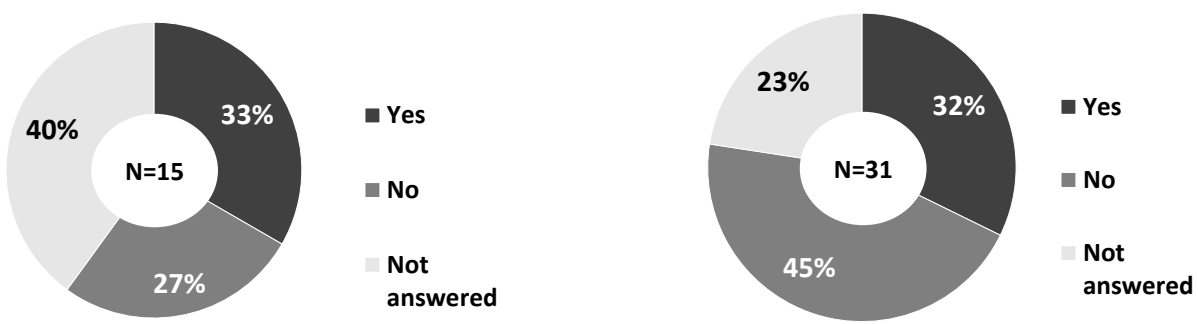

B) Are you aware of any TOD projects near your agency's transit stations/within your municipal boundaries that have made an explicit effort to attract or cater to older adults?
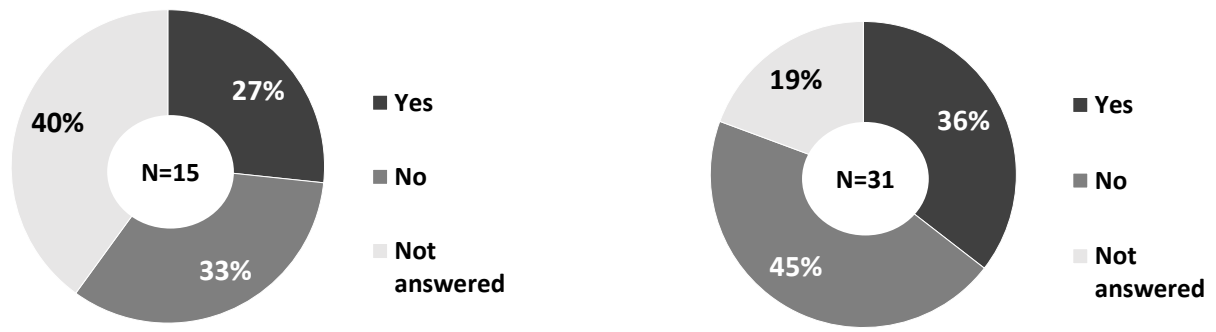

Figure 3. Percentage of transit agencies and local governments that identified: a) station areas with high concentration of older adults and b) TOD projects focus to attract older adults

The Utah Transit Authority (UTA) identified high concentrations of older adults at their (1) Midvale station (Blue Line), (2) Meadowbrook station (Blue Line), and (3) Roy station (FrontRunner). The UTA representative saw the presence of more than a dozen senior living residences near these stations as 
the key to attracting older residents to live there. It is important to note that most of these senior housing projects opened after the rail system began operation.

The respondent from San Diego Metropolitan Transit System (MTA) identified the H Street Station from the Trolley Blue Line as the only station with a high concentration of older adults. According to the MTA representative, the main characteristic that attracted older populations to this station is the presence of high-rise apartments. These apartments attract a higher concentration of people overall and it may be that the existence of luxury-style apartments may suit higher income older adults that are common to that region.

Roughly $32( \pm 16)$ percent of local governments say they have stations areas within their municipal boundaries with high concentrations of older adults $(\mathrm{n}=10)$ (Figure 3$)$. The main reasons given for why these concentrations have occurred include:

- The presence of affordable housing $(n=4)$

- The presence of age-restricted housing $(\mathrm{n}=2)$

- Proximity to specific neighborhoods, such as Chinatown $(\mathrm{n}=2)$

- The presence of mixed-uses $(\mathrm{n}=1)$

Local governments believed that the presence of affordable housing near stations $(n=4)$ is one of the most important reasons why there is a high concentration of older adults. For instance, the city of Philadelphia has several senior housing buildings located within a walking distance to the Suburban, Market East and Lombard South stations. Likewise, there are more than 25 hospitals located in the city, and many of them are located near transit stations. This suggests that the presence of hospitals and health facilities are key elements in attracting older residents to live in TOD neighborhoods. While it is not possible that a hospital can be placed at more than a few stations, transit agencies or local governments interested in creating TOD for older adults may have success by putting a high priority on locating stations near existing hospitals.

Respondents from Pennsylvania and San Francisco mentioned that being near specific neighborhoods (e.g., Chinatown) is a reason that a station might have a high concentration of older adults. As with hospitals, transit agencies or local governments that place a higher priority on locating their stations near such neighborhoods may have greater success in encouraging TOD for older adults.

Upon further investigation, we found that most of the stations that the survey respondents indicated had a high concentration of older adults did, in fact, have a larger than average percentage. Table 2 presents a list of the stations indicated by respondents and the actual population of older adults from 2000 and 2010. By 2010, most had an older adult population of more than 13 percent, which was the national average according to the US census. Further, most of these stations $(n=7)$ have seen an increase in the percentage of older adults between 2000 and 2010. For those stations that did not reach the national percentage of older population $(n=6)$, we found that three of them (Leander Station at Capital Metro, Roy Station, Meadowbrook Station and Midvale Fort Union at UTA) had experienced growth in older populations between 2000 to 2010 . 
Table 2. Population change of adults 65-plus at different stations from 2000 to 2010

\begin{tabular}{|c|c|c|c|c|c|c|c|c|c|}
\hline \multirow{3}{*}{$\begin{array}{l}\text { State } \\
\mathrm{CA} \\
\end{array}$} & \multirow{3}{*}{$\begin{array}{l}\text { Agency } \\
\text { BART } \\
\end{array}$} & \multirow{3}{*}{$\begin{array}{l}\text { Station name } \\
\text { Montgomery St. }\end{array}$} & \multicolumn{3}{|c|}{2000} & \multicolumn{3}{|c|}{2010} & \multirow{3}{*}{$\begin{array}{r}2000- \\
2010 \\
5 \% \\
\end{array}$} \\
\hline & & & \multirow{2}{*}{$\begin{array}{c}\text { Total } \\
13149 \\
\end{array}$} & \multicolumn{2}{|c|}{$65+$} & \multirow{2}{*}{\begin{tabular}{r|} 
Total \\
15146 \\
\end{tabular}} & \multicolumn{2}{|c|}{$65+$} & \\
\hline & & & & 3148 & $24 \%$ & & 3292 & $22 \%$ & \\
\hline $\mathrm{CA}$ & BART & Powell St. & 34220 & 5802 & $17 \%$ & 38255 & 6240 & $16 \%$ & $8 \%$ \\
\hline $\mathrm{CA}$ & Metro & Chinatown Station & 8644 & 1422 & $16 \%$ & 9238 & 1270 & $14 \%$ & $-11 \%$ \\
\hline $\mathrm{CA}$ & Metro & $\begin{array}{l}\text { Little Tokyo / Arts } \\
\text { District Station }\end{array}$ & 6113 & 838 & $14 \%$ & 7810 & 1111 & $14 \%$ & $33 \%$ \\
\hline $\mathrm{CA}$ & MTS & H Street Station & 5815 & 819 & $14 \%$ & 6024 & 845 & $14 \%$ & $3 \%$ \\
\hline $\mathrm{CA}$ & MTS & $\begin{array}{l}\text { 25th/Commercial St } \\
\text { Station }\end{array}$ & 14017 & 816 & $6 \%$ & 12561 & 798 & $6 \%$ & $-2 \%$ \\
\hline NM & NMDOT & Santa Fe Depot & 2774 & 493 & $18 \%$ & 2345 & 466 & $20 \%$ & $-5 \%$ \\
\hline NM & NMDOT & South Capitol & 2910 & 528 & $18 \%$ & 2686 & 637 & $24 \%$ & $20 \%$ \\
\hline $\mathrm{PA}$ & PATCO & Market St. Station & 12310 & 1512 & $12 \%$ & 16697 & 2101 & $13 \%$ & $39 \%$ \\
\hline PA & SEPTA & $\begin{array}{l}\text { Lombard-South } \\
\text { Station }\end{array}$ & 25939 & 2810 & $11 \%$ & 28752 & 2769 & $10 \%$ & $-1 \%$ \\
\hline PA & SEPTA & Suburban Station & 17923 & 3950 & $22 \%$ & 20170 & 3667 & $18 \%$ & $-7 \%$ \\
\hline $\mathrm{TX}$ & $\begin{array}{l}\text { Capital } \\
\text { Metro }\end{array}$ & Leander Station & 172 & 10 & $6 \%$ & 823 & 30 & $4 \%$ & $211 \%$ \\
\hline $\mathrm{UT}$ & UTA & Roy Station & 1900 & 211 & $11 \%$ & 2834 & 320 & $11 \%$ & $51 \%$ \\
\hline UT & UTA & Meadowbrook Station & 1543 & 111 & $7 \%$ & 1662 & 134 & $8 \%$ & $20 \%$ \\
\hline UT & UTA & Midvale Fort Union & 3578 & 268 & $7 \%$ & 3223 & 291 & $9 \%$ & $9 \%$ \\
\hline
\end{tabular}

About $27( \pm 19)$ percent of transit agencies identified specific TOD projects that have the explicit objective to attract older adults $(n=4)$ (Figure 3). When looking at the identified projects, we found that they primarily focused on providing senior housing and no other relevant activities, such as social activities, medical services, and shopping, which have been shown to be important services for older adults.

SunRail in Florida (Orlando) has several examples of TOD projects catering to older adults. For example, the Uptown Maitland Senior Living facility is a 55+ apartment community located within walking distance of the Maitland Station. Another project is the Heritage Village Common, which is senior affordable housing located less than quarter mile from the Longwood rail station north of Orlando. Both housing projects had a waiting list before their openings, indicating that there may be unmet demand for affordable senior housing near transit stations.

Roughly $36( \pm 16)$ percent of local governments identified TOD projects within their municipal boundaries that have made an explicit effort to attract older adults (Figure 3). Some of the projects mentioned by local governments share similar characteristics to those mentioned by transit agencies. However, some municipalities listed projects that are not focused on attracting older residents, which again suggests that they have not yet carefully considered how TOD can serve older adults. For instance, the city of Miami mentioned Vista Grande, Brickell and West Brickell Apartments as aging-focused TOD projects located near transit stations. However, these are low-income housing projects for the general population. 


\section{$5 \quad$ Conclusions and policy implications}

Now that the U.S. population is already the oldest in its history, it is important to have places where the aging population can safely get around without a car, enjoy public spaces, and find the services they need. Nevertheless, cities are unprepared to meet the escalating needs for affordability, accessibility, social activities, and support services that older adults might need. TOD could theoretically be a good means of providing older adults with enhanced opportunities for maintaining mobility and quality of life. Therefore, there is a potential opportunity for transit agencies and local governments to encourage TODs with walkable places, access to cultural activities, safe and affordable transportation, adequate housing, and a range of services for current generations of older adults, as well as generations to come.

This study surveyed practitioners with the broad goal of developing a better understanding of what is being done to encourage TOD for older adults and what might be preventing such efforts. The following paragraphs summarize how the survey results address the specific research questions that we previously outlined and suggest additional research that could more fully address them. While the small sample and other survey limitations prevent definitive answers, the survey responses provide valuable insights and clearly contribute towards answering these questions

The first research question this study seeks to address is the degree to which the relevant government entities are actively encouraging TOD for older adults. We found that, notwithstanding most transit agencies and local governments mentioned having practices aimed at improving transport for older adults and also improving TOD options, far fewer indicated they made any effort to encourage TOD specifically for older adults. Further, those that did respond that they had practices to encourage TOD for older adults largely provided vague and limited examples of their efforts.

The lack of detail in their description of these practices may have resulted from the survey format, and future research could use case studies that use interviews of multiple stakeholders and detailed reviews of planning and policy documents to get a more detailed picture of these practices. However, it is possible that the limited descriptions may simply reflect the limited nature of the practices that are currently used. When we offered respondents the opportunity to elaborate on their initial description of these practices, we received only one response, which may indicate that they didn't have much to add.

In general, our findings indicate that the agencies made little effort to utilize TOD for the benefit the older adults in their communities. As such, it seems there is much room for new and innovative planning practices that can make TOD more responsive to the needs and preferences of older adults.

Only one of the respondents (Cleveland's transit agency) provided evidence of any formal plan or policy regarding TOD for older adults: The Northeast Ohio Areawide Coordinating Agency (NOACA) Regional TOD Scorecard and Implementation Plan. As previously outlined, this plan effectively links TOD with "aging in place" and could serve as a policy blueprint for other agencies seeking to encourage TOD for older adults. The success of this plan should be carefully tracked in terms of ease of implementation and how well implemented plan elements improve the mobility and quality of life for older adults in the Cleveland region.

The second research question seeks to determine the barriers to providing TOD for older adults. As indicated by our survey, the main barriers include affordability, market issues, and the lack of nearby amenities for older adults. There is a need to attract relevant services and amenities that benefit older adults to TODs or to build stations near such amenities. Therefore, policymakers should consider providing incentives for developers and for older adults that can encourage aging-focused TOD through mechanisms such as pricing, taxes and charges, subsidies, rebates, grants and loans, rewards, and bonds. 
More research is needed to determine which approaches are the most effective at attracting older individuals to this type of development. The lack of such programs with a specific focus TOD for older adults speaks to the need for pilot programs where the impacts of the various policy mechanisms can be evaluated.

Although several of the survey respondents indicated that improving walkability could make TOD more attractive for older adults, only three of the respondents mentioned specific aspects of the pedestrian environment (e.g., hills, lack of sidewalks, walking distances) as barriers to encouraging TOD for older adults. Although most TOD projects tend to be centered around walkability, a pedestrian environment specifically focused on the needs of older adults should ideally be taken into greater consideration. As the literature (as previously cited) clearly demonstrates the importance of walkability to older adults, future work should look more closely at the physical characteristics in the pedestrian environment that would be satisfactory to them.

While practitioners are best positioned to understand some of the barriers, particularly to the degree that these barriers are institutional, fully understanding what prevents older adults from moving to a TOD requires additional research that goes beyond the practitioner perspective. To this end, surveys of older adults are needed to determine the specific types of amenities and incentives that would attract them to a TOD. Further, research is also needed to better understand how developers would react to public initiatives to encourage TOD that would be attractive to older adults.

The final research question relates to whether there are existing examples of TOD that effectively serve the needs of older adults. While most respondents could not point to such an example and/or skipped the relevant questions, some did identify stations and projects that have been successful in attracting older adults. In most cases, it appears that these aging-focused TODs have naturally occurred (as opposed to resulting from direct policy interventions), but more detailed case studies are needed to determine if there were subtle, underlying policies that helped these occur. Our survey reveals these TODs have a variety of aging-focused destinations and services, such as senior centers, senior housing, hospitals and health care services within a walking distance from transit stations. Future work should look more closely at the physical, political and local characteristics around the identified stations to obtain information about what attracts the aging population to live near them.

\section{Acknowledgements}

This research was supported by United States Department of Transportation (USDOT) grant, via the Center for Accessibility and Safety for an Aging Population (ASAP), a Tier 1 University Transportation Center (UTC) at Florida State University (FSU), Florida A\&M University (FAMU), and University of North Florida (UNF). The contents of this manuscript reflect the efforts, views, and opinions of the authors and do not reflect those of the USDOT. 


\section{References}

Adler, G., \& Rottunda, S. (2006 ). Older adults' perspectives on driving cessation. Journal of Aging Studies, 20(3), 227-235.

Atkinson-Palombo, C. (2010). Comparing the capitalisation benefits of light-rail transit and overlay zoning for single-family houses and condos by neighbourhood type in metropolitan Phoenix, Arizona. Urban Studies, 47(11), 2409-2426.

Belzer, D., \& Autler, G. (2002). Transit-oriented development: Moving from rhetoric to reality. Washington, DC: The Brookings Institution Center on Urban and Metropolitan Policy.

Bernick, M., \& Cervero, R. (1997). Transit villages in the 21st century. New York: McGraw-Hill.

Boarnet, M., \& Compin, N. (1999). Transit-oriented development in San Diego County. Journal of the American Planning Association, 65(1), 80-95. Retrieved from https://escholarship.org/uc/ item/52v7c5rr

Brooks, A. (2010). Weaving together vibrant communities through transit-oriented development. Community Investments, 22(2), 7-12.

Brown, A. E. (2016). Rubber tires for residents: Bus rapid transit and changing neighborhoods in Los Angeles, California. Transportation Research Record, 2539, 1-10.

Cervero, R. (1998). The transit metropolis: A global inquiry. Washington, DC: Island Press.

Cervero, R. (2007). Transit-oriented development's ridership bonus: A product of self-selection and public policies. Environment and Planning A, 39(9), 2068-2085.

Cervero, R., \& Sullivan, C. (2011). Green TODs: Marrying transit-oriented development and green urbanism. International Journal of Sustainable Development \& World Ecology, 18(3), 210-18. https:// doi.org/10.1080/13504509.2011.570801

Cervero, R., Ferrell, C., \& Murphy, S. (2002). Transit-oriented development and joint development in the United States: A literature review. TCRP Research Results Digest, 52, 1-99. http://onlinepubs.trb. org/onlinepubs/tcrp/tcrp_rrd_52.pdf

Cervero, R., Murphy, S., Ferrell, C., Goguts, N., \& Tsai, Y.-H. (2004). Transit-oriented development in the United States: Experiences, challenges, and prospects. Washington, DC: Transportation Research Board.

Chapple, K., \& Zuk, M. (2016). Forewarned: The use of neighborhood early warning systems for gentrification and displacement. Cityscape, 18(3), 109.

Chatman, D. G., \& DiPetrillo, S. E. (2010). Eliminating barriers to transit-oriented development. Washington, DC: New Jersey Department of Transportation and Federal Highway Administration.

Chihuri, S., Mielenz, T., DiMaggio, C., Betz, M., DiGuiseppi, C., Jones, V., \& Li, G. (2016). Driving cessation and health outcomes in older adults. The Journal of the American Geriatrics Society, 64(2), 332-341.

Coughlin , J. F., \& D'Ambrosio, L. A. (2012). Aging America and transportation. New York: Springer Publishing Company.

Dill, J. (2008). Transit use at transit-oriented developments in Portland, Oregon, area. Transportation Research Record: Journal of the Transportation Research Board, 2063(1), 159-167.

Dittmar, H., \& Shelley, P. (2004). Defining transit-oriented development: The new regional building block. In The new transit town: Best practices in transit-oriented development (pp. 19-40). Washington, DC: Island Press.

Duncan, M. (2011). The impact of transit-oriented development on housing prices in San Diego, CA. Urban Studies, 48(1), 101-27. https://doi:10.1177/0042098009359958

Duncan, M. (2017). Would the replacement of park-and-ride facilities with transit-oriented development reduce vehicle kilometers traveled in an auto-oriented US region? Transport Policy, 81, 293- 
301.

Eby, D. W., \& Molnar, L. J. (2009). Older adult safety and mobility issues and research needs. Public Works Management \& Policy, 13(4), 288-300.

Fan, Y., \& Guthrie, A. (2012). Winners or losers: Resident perceptions of transit-induced neighborhood change. Transportation Research Record: Journal of the Transportation Research Board, 2276, 89-100.

Fernald, M. (2014). Housing America's older adults: Meeting the needs of an aging population. Cambridge, MA: Joint Center for Housing Studies of Harvard University.

Foley, D., Heimovitz, H., Guralnik, J., \& Brock, D. (2002, August). Driving life expectancy of persons aged 70 years and older in the United States. American Journal of Public Health, 92(8), 1284-1289.

Gould, J. (2015). Aging in suburbia — The must have conversation about driving and homes. Washington, DC: Wava Press.

Harrell, R., Lynott, J., \& Guzman, S. (2014). What Is livable? Community. Washington, DC: AARP Public Policy Institute.

Hess, D. B., \& Lombardi, P. A. (2004). Policy support for and barriers to transit-oriented development in the inner city: Literature review. Transportation Research Record: Journal of the Transportation Research Board, 1887, 26-33.

Kamruzzaman, M., Baker, D., Washington, S., \& Turrell, G. (2014). Advance transit-oriented development typology: Case study in Brisbane, Australia. Journal of Transport Geography, 34, 54-70.

Kerr, J., Rosenberg, D., \& Frank, L. (2012). The role of the built environment in healthy aging: Community design, physical activity, and health among older adults. Journal of Planning Literature, 27(1), 43-60.

Kerschner, H. K., \& Silverstein, N. M. (2018). Introduction to senior transportation: Enhancing community mobility and transportation services. New York: Routledge.

Leistner, D. L., \& Steiner, R. L. (2017). Uber for seniors? Exploring transportation options for the future. Transportation Reserach Record: Journal of the Transportation Research Board, 2660(1), 22-29.

Lund, H. (2006). Reasons for living in a transit-oriented development, and associated transit use. Journal of the American Planning Association, 72(3), 357-366.

Marottoli, R. A., Mendes Leon, C. F., Glass, T. A., Williams, C. S., Cooney, L. M., Berkman, L. F., \& Tinetti, M. E. (1997). Driving cessation and increased depressive symptoms: Prospective evidence from the New Haven EPESE. Journal of the American Geriatrics Society, 45(2), 202-206.

Marquet, O., \& Miralles-Guasch, C. (2015). Neighborhood vitality and physical activity among the elderly: The role of walkable environments on active aging in Barcelona, Spain. Social Science \& Medicine, 135, 24-30.

Mathur, S., \& Ferrell, C. (2013). Measuring the impact of sub-urban transit-oriented developments on single-family home values. Transportation Research Part A: Policy and Practice, 47, 42-55.

Michael, Y. L., Green, M. K., \& Farquhar, S. A. (2006). Neighborhood design and active aging. Health \& Place, 12(4), 734-740.

Nasri, A., \& Zhang, L. (2014). The analysis of transit-oriented development (TOD) in Washington, DC and Baltimore Metropolitan areas. Transport Policy, 32, 172-79.

Newman, P., Beatley, T., \& Boye, H. (2017). Create sustainable mobility systems. In Resilient Cities (pp. 53-87). Washington, DC: Island Press.

NOACA. (n.d.). Transit-oriented development (TOD). The Northeast Ohio Areawide Coordinating Agency (NOACA). Retrieved from https://www.noaca.org/regional-planning/transportation-planning/transit-planning-tod/transit-oriented-development-tod

Ragland, D. R., Satariano, W. A., \& MacLeod, K. E. (2005). Driving cessation and increased depressive symptoms. The Journals of Gerontology Series A: Biological Sciences and Medical Sciences, 60(3), 
399-403.

Rayle, L. (2015). Investigating the connection between transit-oriented development and displacement: Four hypotheses. Housing Policy Debate, 25(3), 531-548.

Renne, J. (2017). Make rail (and transit-oriented development) great again. Housing Policy Debate, 27(3), 472-75. https://doi.org/10.1080/10511482.2017.1298213

Renne, J., Tolford, T. L., Hamidi, S., \& Ewing, R. (2016). The cost and affordability paradox of transitoriented development: A comparison of housing and transportation costs across transit-oriented development, hybrid and transit-adjacent development station typologies. Housing Policy Debate, 26(4-5), 819-834.

Rosenbloom, S. (2003). The mobility needs of older Americans: Implications for transportation reauthorization. Washington, DC: The Brookings Institution, Series on Transportation Reform.

Rosenbloom, S. (2009). Meeting transportation needs in an aging-friendly community. Journal of the American Society on Aging, 33(2), 33-43.

Schlossberg, M., \& Brown, N. (2004). Comparing transit-oriented development sites by walkability indicators. Transportation Research Record: Journal of the Transportation Research Board, 1887(1), 34-42.

Sweeney, M. (2004). Travel patterns of older Americans with disabilities. Washington, D.C.: Bureau of Transportation Statistics. https://rosap.ntl.bts.gov/view/dot/6344 